\title{
Klasifikasi Tingkat Kematangan Kopra Mengunakan Metode naïve bayes
}

\author{
Yunaldi M.Z. Masi Adang ${ }^{1}$, Abd.Rabi $^{2}$, M.Kom dan Rahman Arifuddin ${ }^{3}$ \\ 1 Program Studi Teknik Elektro, Universitas Merdeka Malang \\ 2 J1. Taman Agung, Karangbesuki, Kec. Sukun, Kota Malang, Jawa Timur 65146 \\ e-mail: aldyadang21@gmail.com
}

\begin{abstract}
Abstrak-Negara Indonesia memiliki banyak jenis macam perkebunan, salah satunya yaitu perkebunan kelapa. Salah satu bentuk pengolahan kelapa adalah dengan menjadikannya kopra. Kopra adalah kelapa yang telah dikeluarkan isinya dan dikeringkan. Pengeringan kopra biasanya dengan cara pengasapan, dan pengeringan dibawah sinar matahari. Perkembangan perangkat keras dan perangkat lunak komputer yang begitu cepat dan didukung konsep data mining berupa klasifikasi pola serta teknik-teknik pengolahan citra, maka diharapkan penentuan klasifikasi kualitas kopra dengan bantuan komputer dapat direalisasikan untuk membantu mempercepat pekerjaan manusia pada umumnya dan penjual kopra secara khususnya. tujuan penelitian ini adalah membangun aplikaasi untuk memperdiksi persentase kekeringan sampel daging kelapa (kopra). Salah satu cara meningkatkan nilai ekonomis kopra terutama untuk pasar ekspor dan mempermudah petani dalam membedakan kualaitas kopra dan harga jual menjadi lebih baik sesuai dengan tingkat kematangannya. Dengan memperhatikan hal tersebut maka penulis melakukan penelitian dengan judul "Klasifikasi Tingkat Kematangan Kopra Mengunakan Metode Segmentasi Naive Byes"'.
\end{abstract}

Kata kunci- Kopra , Raspberry pi, Kamera, Citra Digital

\begin{abstract}
Indonesia has many types of plantations, one of which is coconut plantations. One form of coconut processing is by making it copra. Copra is coconut that has been extracted and dried. Copra drying is usually by fogging, and drying in the sun. The development of computer hardware and software is so fast and supported by the concept of data mining in the form of pattern classification and image processing techniques, it is expected that the determination of copra quality classifications with the help of computers can be realized to help speed up human work in general and copra tokeh in particular. the purpose of this study was to develop an application to predict the percentage of coconut meat (copra) drought. One of the ways to improve copra economic value is mainly for the export market and it is easy for farmers to differentiate copra quality and selling price according to their level of maturity. With that in mind, the authors conducted a studyoentitled "Copra Maturity Classification Using the Digital Image Naive Byes".
\end{abstract}

Keywords - Copra, Raspberry pi, Camera, Digital Image

\section{Pendahuluan}

Negara Indonesia memiliki banyak jenis macam perkebunan, salah satunya yaitu perkebunan kelapa. Kelapa merupakan salah satu jenis tanaman perkebunan yang sudah lama di budidayakan di indonesia karena memiliki nilai ekonomis yang cukup tinggi dan memiliki peranan penting bagi pertumbuhan perekonomian bagi masyarakat. Salah satu bentuk pengolahan kelapa adalah dengan menjadikannya kopra. Kopra adalah kelapa yang telah dikeluarkan isinya dan dikeringkan. Pengeringan kopra biasanya dengan cara pengasapan, dan pengeringan dibawah sinar matahari. Dan kopra yang dijual di pasaran biasanya masi tercampur antara kopra-kopra yang sudah kering atau belum kering, sehingga membuat pembeli dan penjual kesulitan dalam hal menetukan kualitas dan kelas kopra tersebut. Sehingga hal ini dapat merugikan penjual kopra karena penentuan yang sepihak dan masih kurang akurat. Sehingga diperlukan pengamatan khusus terhadap daging kopra terlebih dahulu untuk memperoleh pengukuran kualitas kopra yang akurat [1]. Perkembangan perangkat keras dan perangkat lunak komputer yang begitu cepat dan didukung konsep data mining berupa klasifikasi pola serta teknik-teknik pengolahan citra, maka diharapkan penentuan klasifikasi kualitas kopra dengan bantuan komputer dapat direalisasikan untuk membantu mempercepat pekerjaan manusia pada umumnya serta pembeli dan penjual kopra secara khususnya. Oleh karena itu tujuan penelitian ini adalah membangun aplikasi untuk memprediksi persentase kekeringan kopra. Dengan melakukan sortasi atau seleksi sebelum dilakukan distribusi kepasar. Dan hal ini bertujuan juga untuk meningkatkan nilai ekonomis kopra terutama untuk pasar ekspor dan mempermudah petani dalam membedakan kualaitas kopra dan harga jual menjadi lebih baik sesuai dengan tingkat kematangannya. Dengan memperhatikan hal tersebut maka dilakukan penelitian dengan judul "Klasifikasi Tingkat Kematangan Kopra Mengunakan Metode Naïve Bayes', 


\section{Studi Pustaka}

\subsection{Raspberry Pi}

Raspberry pi merupakan sebuah mini pc. Secara fungsional tidak berbeda dengan komputer seperti umumnya, raspberry pi bisa digunakan untukoaktivitas komputer. Raspberry pi membutuhkan daya listrik yang sangat sedikit untuk beroperasi, kelebihan dari raspberry $p i$ terletak pada pin-pin yang bisa diprogram untuk mengumpulkan data atau mengendalikan modul sensor yang membutuhkan pin sebagai portoserial nya [4].

Raspberry pi menggunakan sistem operasi berbasis linux dilengkapi dengan menggunakan prosesor ARM Cortex-A53 dari broadcom, dengan spesifikasi 64bit Quad-Core dan berkecepatan 1,2 Ghz dan ram $1 \mathrm{~GB}$ serta dilengkapi dengan 4 port USB dan sebuah pengendali Ethernet [4]. Raspberry pi mempunyai slot kartu SDcard. SDcard ini berfungsi sebagai media penyimpanan file-file dan juga sistem operasi yang disimpan dalam kartu SDcard.

\subsection{Modul Kamera Raspberry pi Noir V2.}

Modul kamera raspberry pi NoIR v2 adalah sensor gambar/ kamera yang menggunakan sensor sony IMX219 dengan piksel sebesar 8 megapiksel, berkualitas tinggi yang dirancang khusus add-onoboard untuk raspberry pi, menampilkan lensa fokus. Gambar Statis yang dihasilkan 3280 x 2464 piksel, dan juga mendukung video 1080p30, 720 p60 dan 640x480p60 / 90. Modul kamera raspberry pi NoIR v2 pemasangannya yaitu dengan menghubungkan langsung melalui kabel fleksible pada board raspberry pi melalui salah satu soket kecil di permukaan atas board raspberry pi dan menggunakan antar muka CSi khusus yang dirancang, khusus untuk antar muka ke kamera.

\subsection{Motor Servo}

Motor servo merupakan motor DC dengan gearbox dan sistem kontrol menggunakan pulsa sebagai penggerak. Sistem kontrol motor servo akan memberikan sinyal pulse ke posisi putaran motor dari $0^{\circ}$ sampai $180^{\circ}$. Motor servo juga memiliki torsi relatif cukup kuat, karena motor servo disusun oleh variabel resistor, gearbox, motor dc dan sistem kendali. 3 kabel yang dimiliki motor servo yaitu kabel power, kabel GND dan kabel data. Kontrol PWM (Pulse Width Modulation) yang diberikan pada motor servo membuat servo dapat bergerak dengan posisi tertentu dan setelah itu berhenti setelah diberi pulse PWM.

\subsection{Computer Vision}

Computer Vision merupakan bidang ilmiah yang dapat mengenali objek dari sebuah gambar atau video dengan menggunakan komputer. Arti computer vision adalah teknologi mesin yang dapat melihat, dimana teknologi ini mampu mengekstrak informasi gambar yang ditangkap untuk menyelesaikan tugas tertentu. Sebagai bidang ilmu komputer yang berkaitan dengan data gambar dapat yang diambil, seperti foto, video, pandangan dari kamera real time, atau data dari scanner medis.

\subsection{Open $\mathrm{CV}$}

Open $C V$ adalah Open Source Computer Vision merupakan library dari computer vision dibuat oleh perusahaan Intel Corporation yang bersifat terbuka, Kumpulan beberapa bahasa $\mathrm{C}$ dan bahasa $\mathrm{C}++$ pada library Open $C V$ ini mengimplementasikan semua algoritma komputer vision dan juga algoritma image processing. Penerapan program Open $C V$ dalam dunia robotika mempunyai library Open $C V$ memiliki 2500 lebih algoritma yang sudah dioptimalkan, algoritma dari Open $C V$ meliputi sebuah himpunan keseluruhan yaitu himpunan klasik dan himpunan seni, beberapa algoritma machine learning dan juga algoritma computer vision.

\subsection{Contour}

Pada dasarnya, Contour digunakan untuk proses pendeteksian tepi guna mengolah lebih lanjut mengenai tepian-tepian yang telah terdeteksi. Contour sebagai kumpulan pixel yang merepresentasikan bentuk kurva dalam citra secara teratur. Contour adalah sekumpulan titik yang menggambarkan suatu bentuk dalam sebuah citra. Gambaran ini dapat berbeda sesuai dengan keadaan. Contour sangat cocok digunakan untuk analisis bentuk serta deteksi dan pengenalan suatu objek, hal ini dikarenakan sistem kerja dari contour yang dapat mengenali sebuah kurva yang menghubungkan setiap titik yang berkelanjutan dalam sebuah batas.

\subsection{Background Substraction}

Background subtraction merupakan salah satu tugas penting yang pertama kali di kerjakan pada aplikasi computer vision. Output dari background subtraction biasanya adalah inputan yang akan diproses pada tingkat yang lebih lanjut lagi seperti tracking objek yang teridentifikasi. Kualitas background subtraction umumnya tergantung pada teknik pemodelan background yang digunakan untuk mengambil background dari suatu layar kamera. Background subtraction biasanya digunakan pada teknik segmentasi objek yang dikehendaki dari suatu layar, dan sering diaplikasikan untuk sistem pengawasan.

\subsection{Metode NaïveoBayes}

Nä̈ve Bayes Classifier merupakan sebuah metode klasifikasi yang berakar pada teorema Bayes. Metode pengklasifikasian dengan menggunakan metode probabilitas dan statistik yang dikemukakan oleh ilmuwan Inggris Thomas Bayes, yaitu memprediksi peluang di masa depan berdasarkan pengalaman di masa sebelumnya sehingga dikenal sebagai Teorema Bayes. Ciri utama dari Naïve Bayes Classifier ini adalah asumsi yang sangat kuat (naif) akan independensi dari masing-masing kondisi / kejadian. Menurut Olson Delen (2008) menjelaskan Naïve Bayes untuk setiap kelas keputusan, menghitung probabilitas dengan syarat bahwa kelas keputusan adalah benar, mengingat vaktor informasi obyek. Algoritma ini mengasumsikan bahwa atribut obyek adalah independen. Probabilitas yang terlibat dalam memproduksi perkiraan akhir dihitung sebagai jumlah frekuensi dari "master" tabel keputusan.

\subsection{Integral Image}

Integral Image digunakan sebagai menentukan sampel ada atau tidaknya di dalam ratusan fitur dalam sebuah gambar dengan cepat dan dengan skala berbeda secara efisien. 


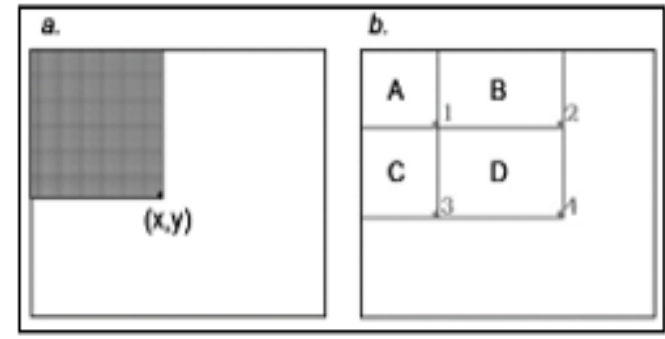

Gambar 1. Integral Image

Seperti pada gambar 1. Bagian a. mengintegrasikan, nilai pada piksel sumbu (x,y) berisi jumlah semua piksel di dalam daerah segi empat mulai dari kiri atas sampai pada lokasi sumbu (x, y) atau daerah yang diarsir Untuk memperoleh nilai piksel pada daerah yang diarsir (area segiempat) ini hanya bisa dilakukan dengan membagi nilai sumbu (x, y) pada area yang berbentuk segi empat.

$$
i i(x, y)=\sum_{x^{\prime} \leq x, y^{\prime} \leq y} i\left(x^{\prime}, y^{\prime}\right)
$$

Dimana $i$ sumbu $(x, y)$ merupakan integral image dan $i$ sumbu ( $x$, $\left.y^{\prime}\right)$ adalah original image.

Pada gambar 1. Bagian b. Dari operasi ini, suatu karakteristik dapat diekstraksi dalam waktu yang konstan pada gambar integral dengan menambahkan dan mengurangi nilai-nilai simpul untuk setiap persegi panjang. Untuk yang lebih besar kejelasan, pada gambar jumlah piksel yang membentuk persegi panjang D dapat dihitung sebagai

$$
\text { Sum } D=(4+1)-(2+3)
$$

Dimana 1, 2, 3, 4, adalah nilai yang diberikan dalam gambar yang terintegrasi di lokasi tersebut.

maka proses perulangan akan terus berlanjut sampai dengan Fn.

\section{Metode}

Metode pada penelitian ini akan menjelaskan mengenai proses perancangan dan variabel yang akan diteliti sehingga mempermudahkan penyelesaian tugas akhir.

\subsection{Variabel Penelitian}

Variable yang digunakan dalam penelitian ini adalah dengan melakukan pemrosesan terhadap 30 citra yang berekstensi *bmp atau *jpg. Dari 30 jenis citra tersebut akan diproses menggunakan metode transformasi warna HSI. Dan RGB. Diambil sampel sebanyak 10 buah pada masing-masing kondisi kopra yaitu standar,bagus dan sangat bagus. Citra kopra dengan format bitmap atau jpeg di croping bagian daging kopra dan dihitung histogram RGB-nya dengan dilakukan transformasi ruang warna RGB ke ruang warna HSI. maka setiap citra sampel dengan format bitmap atau jpeg. Jumlah sampel yang digunakan untuk proses analisis adalah 30 citra yang berekstensi *jpg. Dari 30 jenis citra tersebut akan diproses menggunakan metode transformasi warna HIS dan ruang warna RGB.

\subsection{Parameter}

Di dalam perancangan pembuatan alat terdapat parameter yang digunakan. Perancangan yang akan diteliti serta dianalisis dengan harapan diperoleh data-data mengenai kinerja alat untuk mendeteksi suatu citra digital Jarak merupakan besaran skalar yang mengacu pada panjang objek yang ditangkap oleh kamera dan juga waktu yang dibutuhkan raspberry pi untuk memproses objek citra digital menggunakan sebuah metode yang diterapkan pada library Open $C V$.

\subsection{Model Arsitektur Skema}

Tugas akhir ini akan dirancang alat penyortir kopra yang mendeteksi objek dan memilah hasil sesuai dengan kelompok sampel kopra masing-masing kelasnya, yang dideteksi oleh kamera dan motor servo mulai bergerak memilah sampelnya masing-masing. Agar sesuai dengan input data yang dimasukan. Alur bagan perancangan alat ialah sebagai berikut:

1. Kamera digunakan sebagai penangkap citra digital untuk diproses raspberry pi.

2. Raspberry pi bertugas sebagai mini-pc untuk memproses citra digital yang dideteksi dan menggerakkan kepala untuk mengikuti objek.

3. Servo sebagai penggerak palang pemilah pada konveyor.

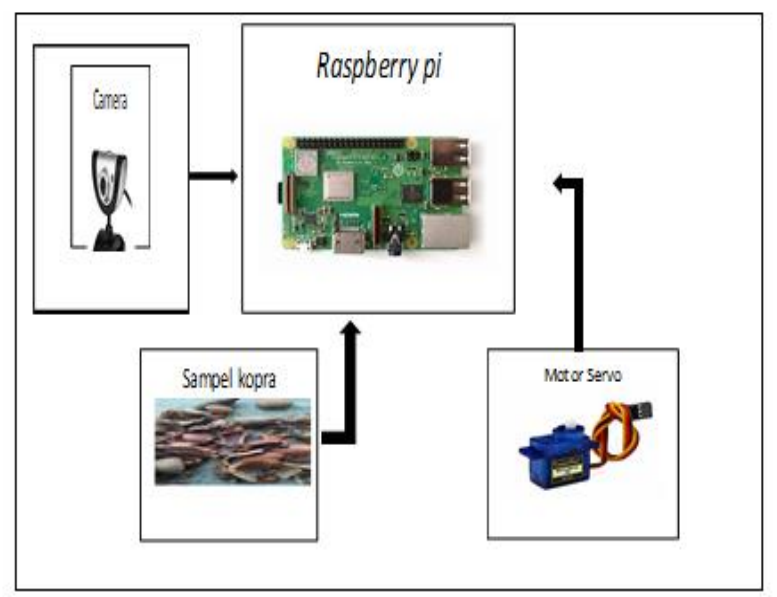

Gambar 2. Bagan Perancangan Sitem Sortir

Pada gambar 2 dijelaskan bahwa kamera digunakan untuk mengambil data berupa gambar real time kemudian raspberry pi memproses hasil citra digital yang ditangkap kamera untuk proses digunakan library open $c v$ yang telah terinstal pada raspberry pi, file gambar real time yang telah terbaca akan diproses menggunakan metode nä̈ve bayes setelah kopra terdeteksi oleh kamera selanjutnya raspberry pi akan mengontrol 4 servo yang akan menjadi aktuator dari mesin sortir.

\subsection{Flowchart system}

Flowchart program pada penelitian ini untuk memproses data berupa citra yang ditangkap kamera berupa objek dan proses pada raspberry pi secara real-time. Tampilan flowchart dapat dilihat pada gambar 3. dijelaskan pengkondisian awal sistem dan input yang harus dilakukan pada sensor kamera agar input data berupa citra digital yang dideteksi kamera dapat dibaca oleh raspberry pi dan mini pc adalah kunci untuk memproses data yang dibaca oleh kamera serta memberi keputusan untuk menentukan kamera dapat mendeteksi dan mengelompan sampel -sampel kopra dan raspberry pi mengontrol motor servo untuk 
menggerakkan palang pemilah humanoid agar memilah objek yang dideteksi melalui kamera.

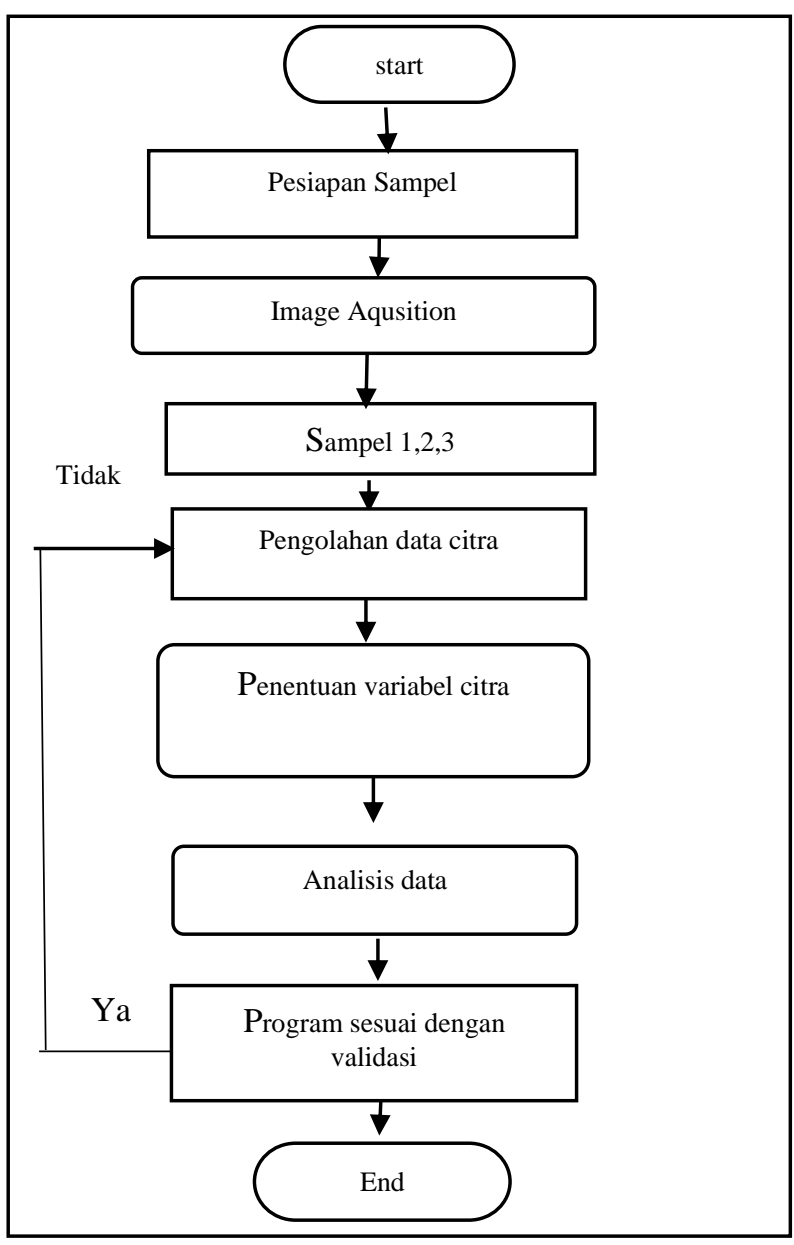

Gambar 3. Flowchart system

\subsection{Skematik Rangkaian}

Skematik rangkaian yang menghubungkan semua komponen di rancang pada Gambar 4

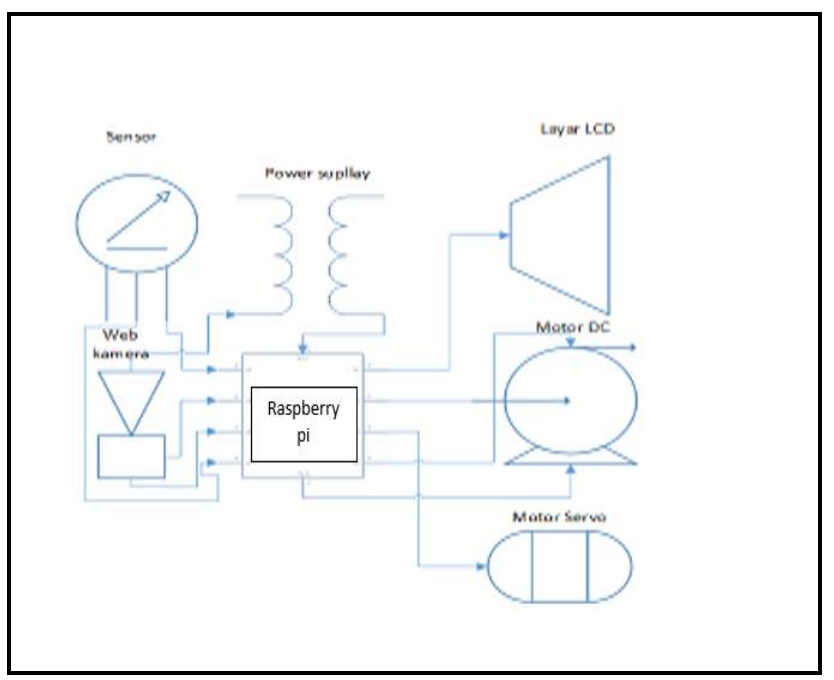

Gambar 4. Skematik Rangkaian

Gambar 4 Menunjukkan perancangan hardware raspberry pi sebagai mini pc, kamera yang dihubungkan pada port USB raspberry pi yang tersedia, driver motor PCA9685 untuk kendali servo yang dihubungkan pada pin GPIO pada raspberry pi dan motor servo untuk penggerak pada kepala robot humanoid yang sudah terpasang pada driver servo PCA9685.

\section{HaSil dan Pembahasan}

Pada penelitian ini terdapat Pengujian dan perancangan alat sortir . Pada pengujian pertama yang dilakukan untuk mengetahui proses pendeteksi gambar sampel pada citra digital. Citra diperoleh secara real-time, pengujian dilakukan dengan menguji hasil dari perancangan alat sortir.

\subsection{Pengujian Citra Yang Di Deteksi Web Kamera}

Langkah awal dalam melakukan deteksi sampel kopra adalah melakukan training data set agar program dapat menyimpan berbagai klasifikasi untuk membentuk skema sampel kopra. Selanjutnya adalah kamera akan disiapkan untuk mengambil data kamera secara real time. Web kamera berfungsi sebagai sensor untuk mendeteksi out put berupa kopra yang akan mengelompokkan kopra sesuai dengan kelasnya masing ditunjukkan pada Gambar 4.1 berikut

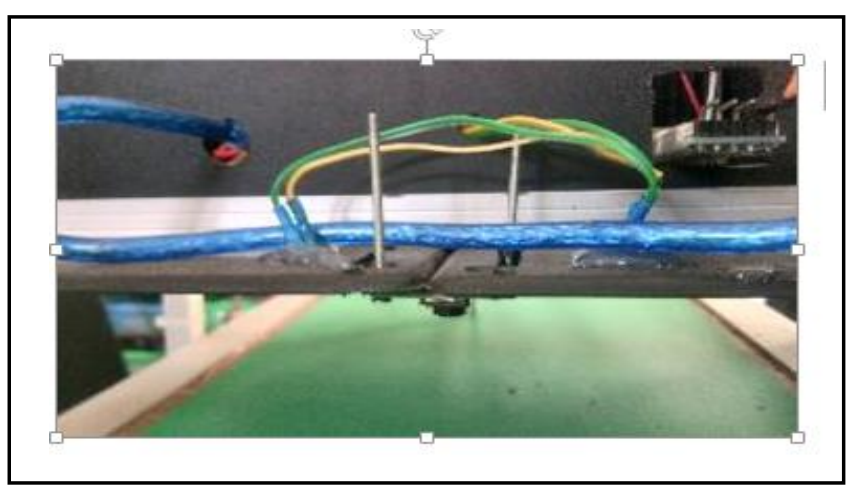

Gambar 4.1. Web Kamera

\begin{tabular}{|c|c|c|c|c|c|}
\hline Tahap & $\begin{array}{c}\text { Jenis } \\
\text { Kopra }\end{array}$ & Merah & Hijau & Biru & $\begin{array}{c}\text { Jumlah } \\
\text { Citra }\end{array}$ \\
\hline $\begin{array}{c}\text { Pengujian } \\
1\end{array}$ & KW 3 & 223.51 & 200.60 & 159.75 & 12 \\
\hline $\begin{array}{c}\text { Pengujian } \\
2\end{array}$ & KW2 & 220.53 & 176.81 & 130.69 & 12 \\
\hline $\begin{array}{c}\text { Pengujian } \\
3\end{array}$ & KW1 & 183.00 & 143.37 & 109.32 & 12 \\
\hline
\end{tabular}

Tabel 4.1. Proses Penentuan Kualitas Kopra 
A. Gambar Hasil Pengujian Sampel Kopra Mengunakan Matlab

Pada prose ini dilakukan pengujian tiap-tiap sampel kopra megunakan software matlab. Proses ini bertujuan untuk menampilkan gambar dari sampel kopra KW 1, KW 2, KW 3, yang selisi nilai RGB sudah terterah pada tabel sebelumnya. Berikut adalah gambar - gambar sampel kopra KW 1, KW 2, KW 3.

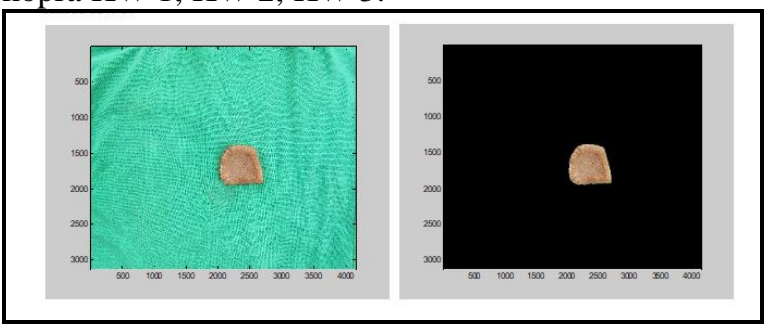

Gambar 4.2. Sampel Kopra KW 1 Pada Matlab

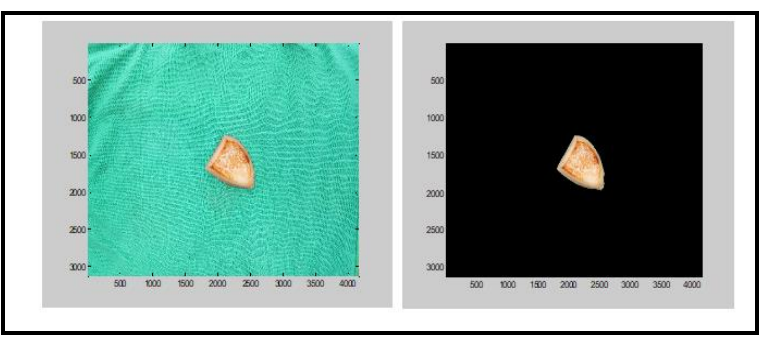

Gambar 4.3. Sampel Kopra KW 2 Pada Matlab

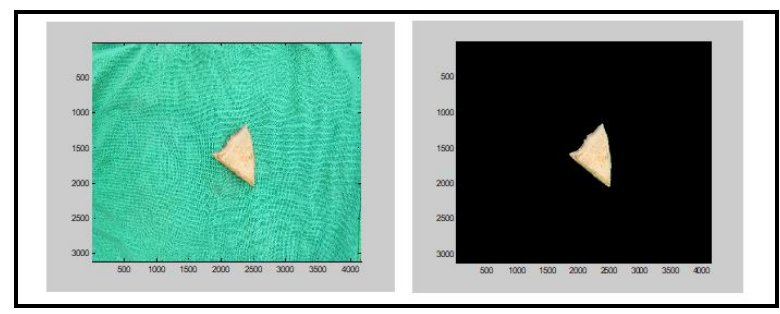

Gambar 4.4. Sampel Kopra KW 3 Pada Matlab

Ke 3 gambar ini merupakan contoh data citra real time sebagai input. Untuk melakukan proses pengelompokan citra gambar kopra, dan data akan diproses dengan metode integral image melakukan perhitungan nilai citra pada empat buah titik dan membuat representasi citra baru.

Selanjutnya nilai yang diperoleh akan diproses menggunakan metode nä̈ve baayes dengan menghitung selisih dari jumlah piksel dari daerah. roses selanjutnya yaitu nilai yang telah diperoleh dari ekstraksi fitur haar akan dibuat sebagai klasifikasi lemah menjadi klasifikasi kuat dengan metode nä̈ve bayes. Setelah didapatkan klasifikasi dengan nä̈ve bayes maka nilai tersebut diproses dengan nä̈ve bayes untuk mengombinasikan banyak fitur.

Proses pengkasifikasian yang menampilkan citra gambar digunakan untuk menunjukkan bahwa kopra terdeteksi. Merupakan hasil dari semua proses face detection menggunakan metode naïve bayes.

\begin{tabular}{|l|r|r|r|r|}
\hline \multicolumn{1}{|c|}{ Nama File } & Merah & \multicolumn{1}{|c|}{ Hijau } & \multicolumn{1}{c|}{ Biru } & Kualitas \\
\hline kopra 1.10_KW1.jpg & 183,0054 & 143,3762 & 109,3233 & KW1 \\
\hline kopra 1.11_KW1.jpg & 192,5556 & 157,1025 & 123,9544 & KW1 \\
\hline kopra 1.12_KW1.jpg & 189,7449 & 153,3618 & 117,2357 & KW1 \\
\hline kopra 1.1_KW1.jpg & 164,8246 & 116,7616 & 82,7576 & KW1 \\
\hline kopra 1.2_KW1.jpg & 133,1045 & 110,8012 & 87,1662 & KW1 \\
\hline kopra 1.3_KW1.jpg & 165,6050 & 119,4642 & 83,1902 & KW1 \\
\hline kopra 1.4_KW1.jpg & 176,7635 & 134,6978 & 97,5841 & KW1 \\
\hline kopra 1.5_KW1.jpg & 164,1562 & 123,0214 & 88,5704 & KW1 \\
\hline kopra 1.6_KW1.jpg & 177,6172 & 136,3036 & 99,7497 & KW1 \\
\hline kopra 1.7_KW1.jpg & 169,3993 & 124,7403 & 85,9676 & KW1 \\
\hline kopra 1.8_KW1.jpg & 165,1437 & 127,5336 & 94,5719 & KW1 \\
\hline kopra 1.9_KW1.jpg & 160,1043 & 127,2325 & 99,2658 & KW1 \\
\hline kopra 2.10_KW2.jpg & 220,5339 & 176,8143 & 130,6999 & KW2 \\
\hline kopra 2.11_KW2.jpg & 210,5119 & 164,5507 & 116,5329 & KW2 \\
\hline kopra 2.12_KW2.jpg & 216,5187 & 173,5865 & 127,2422 & KW2 \\
\hline kopra 2.2_KW2.jpg & 206,7056 & 151,5770 & 99,2670 & KW2 \\
\hline kopra 2.3_KW2.jpg & 210,6955 & 166,4152 & 121,3301 & KW2 \\
\hline kopra 2.5_KW2.jpg & 219,0975 & 177,6940 & 131,6709 & KW2 \\
\hline kopra 2.6_KW2.jpg & 214,9001 & 167,9454 & 122,0245 & KW2 \\
\hline kopra 2.7_KW2.jpg & 213,6354 & 155,6773 & 97,8218 & KW2 \\
\hline kopra 2.8_KW2.jpg & 208,9960 & 157,4959 & 108,1160 & KW2 \\
\hline kopra 2.9_KW2.jpg & 213,8882 & 171,0894 & 125,3044 & KW2 \\
\hline kopra 3.10_KW3.jpg & 223,5118 & 200,6068 & 159,7576 & KW3 \\
\hline kopra 3.11_KW3.jpg & 223,9955 & 199,7691 & 156,8215 & KW3 \\
\hline kopra 3.12_KW3.jpg & 214,9187 & 190,1115 & 148,6505 & KW3 \\
\hline kopra 3.1_KW3.jpg & 222,1415 & 200,1679 & 159,0106 & KW3 \\
\hline kopra 3.2_KW3.jpg & 210,9480 & 181,0461 & 139,3024 & KW3 \\
\hline kopra 3.3_KW3.jpg & 210,8145 & 184,5524 & 146,6976 & KW3 \\
\hline kopra 3.4_KW3.jpg & 210,6511 & 194,4574 & 161,6036 & KW3 \\
\hline kopra 3.5_KW3.jpg & 210,5098 & 187,1241 & 151,7331 & KW3 \\
\hline kopra 3.6_KW3.jpg & 215,5736 & 185,1400 & 140,1303 & KW3 \\
\hline kopra 3.7_KW3.jpg & 217,2731 & 192,7275 & 151,1293 & KW3 \\
\hline kopra 3.8_KW3.jpg & 222,0363 & 198,5878 & 157,6498 & KW3 \\
\hline kopra 3.9_KW3.jpg & 219,5492 & 195,8468 & 156,7009 & KW3 \\
\hline
\end{tabular}

\section{KESIMPULAN}

Berdasarkan hasil pembahasan maka dapat disimpulkan nilai input yang digunakan dalam klasifikasi tahap kematangan kopra variavel yaitu r, g, b, v, *a, *b entropi, energy dan homogenitas dan model 1-3 nilai variabel yaitu r, g, b, v, *a, entropi, dan homogenitas, dan naïve bayes digunakan sebagai metode dalam proses pengklasifikasian dengan cara membandingkan nilai probabilitas yang dihasilkan dari nilai variabel penduga setiap model untuk menentukan tahap kematangan kopra hasil yang diperoleh dari model sampel 1-3 akurasi rataratanya terbesar mencapai $91,12 \%$, dan Naïve bayes layak untuk digunakan sebagai klasifikasi tahap kematangan kopra berdasarkan warna daging kopra. 


\section{REFERENSI}

[1] L. Liu et al., "Deep Learning for Generic Object Detection: A Survey," Int. J. Comput. Vis., 2019.

[2] T. A. S, A. Rabi', D. Minggu, and I. Mujahidin, "Frequency Hopping Video Real Time Untuk Pengamanan Data Pengintaian Operasi Inteligence TNI," JASIEK (Jurnal Apl. Sains, Informasi, Elektron. dan Komputer), 2019.

[3] M. Zhanbyrtayev and B. Kassenov, "A novel approach to mobile indoor navigation systems," 2016.

[4] D. A. Prasetya, A. Sanusi, G. Chandrarin, E. Roikhah, I. Mujahidin, and R. Arifuddin, "Small and Medium Enterprises Problem and Potential Solutions for Waste Management," J. Southwest Jiaotong Univ., vol. 54, no. 6, 2019.

[5] S. Siswanto, D. A. Prasetya, N. Rachman, and B. F. Hidayatulail, "Pengendali Robot Beroda Berbasis Sensor Telemetri Voice Pattern Recognition," JASIEK (Jurnal Apl. Sains, Informasi, Elektron. dan Komputer), 2019.

[6] D. A. Prasetya, A. Sanusi, G. Chandrarin, E. Roikhah, I. Mujahidin, and R. Arifuddin, "Community Culture Improvisation Regarding Waste Management Systems and Per Capita Income Increase," $J$. Southwest Jiaotong Univ., vol. 54, no. 6, 2019.

[7] C. Finn, P. Abbeel, and S. Levine, "Model-agnostic meta-learning for fast adaptation of deep networks," in 34th International Conference on Machine Learning, ICML 2017, 2017.

[8] E. Endrayana, D. H. S. Wahyuni, N. Nachrowie, and I. Mujahidin, "Variasi Ground Plane Antena Collinear Pada Pemancar Telivisi Analog Dengan Frekuensi UHF 442 MHz," JASIEK (Jurnal Apl. Sains, Informasi, Elektron. dan Komputer), vol. 1, no. 2, pp. 149 156, 2019.

[9] M. W. Otte, "A Survey of Machine Learning Approaches to Robotic Path-Planning," Int. J. Rob. Res., 2008.

[10] I. Mujahidin, S. H. Pramono, and A. Muslim, "5.5 Ghz Directional Antenna with 90 Degree Phase Difference Output," 2018.

[11] Y. Lecun, Y. Bengio, and G. Hinton, "Deep learning," Nature. 2015.

[12] I. Mujahidin and P. S. Arinda, "Antena Compact Double Square Marge 2, 6GHz Dengan Output Perbedaan Fase 90 Derajat Untuk Aplikasi LTE," JEECAE (Journal Electr. Electron. Control. Automot. Eng., vol. 4, no. 2, pp. 273-278, 2019.

[13] I. Daubechies, M. Barlaud, and P. Mathieu, "Image Coding Using Wavelet Transform," IEEE Trans. Image Process., 1992.

[14] I. Mujahidin, D. A. Prasetya, A. B. Setywan, and P. S. Arinda,
"Circular Polarization 5.5 GHz Double Square Margin Antenna in the Metal Framed Smartphone for SIL Wireless Sensor," in 2019 International Seminar on Intelligent Technology and Its Applications (ISITIA), 2019, pp. 1-6.

[15] Raspberry Pi Foundation, "Camera Module," Prod. Data, 2016.

[16] B. F. Hidayatulail and I. Mujahidin, "Potential Of 77, $78 \mathrm{~mW}$ Red Diode Laser For Photodynamic," JEEMECS (Journal Electr. Eng. Mechatron. Comput. Sci., vol. 2, no. 2, 2019.

[17] Raspberrypi.org, "Raspberry Pi 2 Model B," Https:/Www.Raspberrypi.Org/Products/Raspberry-Pi-2-Model-B/, 2015.

[18] R. Yuwono and I. Mujahidin, "Rectifier using UWB microstrip antenna as electromagnetic energy harvester for GSM, CCTV and Wi-Fi transmitter," J. Commun., 2019.

[19] V. Vujović and M. Maksimović, "Raspberry Pi as a Wireless Sensor node: Performances and constraints," in 2014 37th International Convention on Information and Communication Technology, Electronics and Microelectronics, MIPRO 2014 - Proceedings, 2014.

[20] J. Lasmono, A. P. Sari, E. Kuncoro, and I. Mujahidin, "Optimasi Kerja Peluncur Roket Pada Robot Roda Rantai Untuk Menentukan Ketepatan Sudut Tembak," JASIEK (Jurnal Apl. Sains, Informasi, Elektron. dan Komputer), 2019.

[21] R. Shokri and V. Shmatikov, "Privacy-preserving deep learning," in 2015 53rd Annual Allerton Conference on Communication, Control, and Computing, Allerton 2015, 2016.

[22] A. E. Pambudi, L. Maajid, J. Rohman, and I. Mujahidin, “Aplikasi Penggunaan Joystick Sebagai Pengendalian Remote Control Weapon Station (RCWS) Senjata Mesin Ringan (SMR)," JASIEK (Jurnal Apl. Sains, Informasi, Elektron. dan Komputer), vol. 1, no. 2, pp. 98-105, 2019.

[23] H. A. M. Alhamzawi, "Faces and eyes Detection in Digital Images Using Cascade Classifiers," Comput. Eng. Appl. J., 2018.

[24] D. F. C. Kusuma, D. A. Prasetya, F. Kholid, and I. Mujahidin, "Evaluasi Database Senjata Untuk Sistem Keamanan Menggunakan Fuzzy Logic,” JASIEK (Jurnal Apl. Sains, Informasi, Elektron. dan Komputer), vol. 1, no. 2, pp. 111-116, 2019.

[25] R. Wiryadinata, "Perancangan Roket Terkendali Penembak Pesawat Dilengkapi Chip Yang Terintegrasi Algoritma Cerdas," in SNATI (Seminar Nasional Aplikasi Teknologi Informasi) 2007, 2007.

[26] T. Kobayashi and N. Otsu, "Image feature extraction using gradient local auto-correlations," in Lecture Notes in Computer Science (including subseries Lecture Notes in Artificial Intelligence and Lecture Notes in Bioinformatics), 2008. 